according to priority). Child-friendly tools included discussions, postcards, toy money and board games.

Results DR and SBR were completed by all participants using the $\mathrm{DR}$ rankings as a baseline then separating equal ranked items to generate SBR rankings. Older children preferred BP as it allowed them to make choices according to need for improvement and therefore requirement for funds, rather than simply importance, but was only used successfully by those aged $8+$

BP can also demonstrate weighting. Managing Acute Attacks was prioritised $1^{\text {st }}$ with all methods but only BP demonstrated strength of opinion: Managing Acute Attacks received £1430 in total, whilst the $2^{\text {nd }}$ place issue received just $£ 610$.

Conclusions Young children can and should be in involved with health services research. More effort needs to be dedicated to developing methods that enable Childrens involvement.

Acknowledgement This project was funded by the NIHR Health Services and Delivery Research programme (project number $09 / 2001 / 19$ ). The views and opinions expressed therein are those of the authors and do not necessarily reflect those of the HS\&DR programme, NIHR, NHS or the Department of Health.

\section{KARATE INFLUENCES ON ASTHMA MANAGEMENT IN PRESCHOOL CHILDREN}

doi:10.1136/archdischild-2012-302724.1698

${ }^{1} \mathrm{~A}$ Bajraktarevic, 'A Pahor Kurilic, 'M Miokovic, 'S Trhulj Putica, 'S Penava, ${ }^{2 B}$ Djukic, ${ }^{2} \mathrm{~L}$ Sporisevic, ${ }^{3} \mathrm{~A}$ Selimovic, ${ }^{3} \mathrm{E}$ Mujicic Selimovic, ${ }^{4} \mathrm{~A}$ Djurdjevic Djulepa, ${ }^{5} \mathrm{Z}$ Zvizdic,

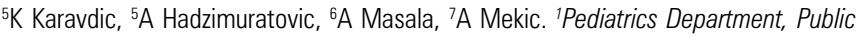
Health Institution of Sarajevo Canton; 'Pediatrcs Department, First Medical Aid; ${ }^{3}$ Pulmonology Department, Pediatrics Clinic; ${ }^{4}$ Pediatrics Departrment, General Hospital Sarajevo; ${ }^{5}$ Pediatrics Surgery, Clinic Surgery for Children; ${ }^{6}$ Sports Department, Ministery of Health Science and Education of Canton Sarajevo; 'Department for Contact Sparing Fighting, Sports Faculty University Sarajevo, Sarajevo, Bosnia-Herzegovina

Background Examples of semi-contact sports include karate and its benefite influence on asthma in childhood. Specific treatment for asthma will be determined by pediatrician based on children age, overall health, medical history, extent of the disease, tolerance for specific medications, procedures, or therapies and expectations for the course of the disease.

Aims A target of this article is showing benefit of karate training in preschool ages on asthma management and course of disease.

Methods To verify the efficacy of karate on asthma, a complex psychomotor activity that enhances pulmonary capacity and lungs volume, and breathing regulations, as an intervention for asthma curing, ten children with asthma, ranging in age from five to seven years, and meeting diagnostic criteria for children asthma disorder were studied during two years period 2010-2011.

Results A higher prevalence of asthma has been reported in athletes specially in karate clubs for younger children but with better control of asthma. Risk ofasthma decreased with number of years of training (odds ratio 2.02; 95\% confidence interval 1.60-3.03; $p<0.0001$ ), number of hours per week (odds ratio 1.74; CI 1.11-2.21; $p=0.015)$ and rank, specifically brown green belt versus lower belts (odds ratio 3.53; CI 2.82-6.28; $p=0.007$ ).

Conclusions Karate is a relatively safe sport for preschool children and younger schoolers when properly taught and optimize for asthma management. These training principles are perhaps most useful early in a children patient's course when the setting of appropriate expectations is important in minimizing restrictions from treatment and karate activity.

\section{DISTRIBUTION OF CONGENITAL MALFORMATION} IN A NEONATAL INTENSIVE CARE UNIT IN TURKEY

doi:10.1136/archdischild-2012-302724.1699
A Dursun, A Zenciroglu, N Hakan, N Karadag, BS Karagol, B Aydin, D Dilli, S Beken, N Okumus. Neonatology, Dr Sami Ulus Maternity and Children's Health and Diseases Training and Research Hospital, Ankara, Turkey

Background and Aim Congenital malformations are one of the important reasons of mortality and morbidity in newborns. The aim of this study is to give the frequency and distribution of the congenital malformation in a neonatal intensive care unit from Turkey.

Method A retrospective analysis of congenital abnormalities in singleton births was performed to identify frequency, types, combined congenital abnormalities and distribution of malformation in newborns over a 7 year period. Congenital malformations were classified according to involved organ systems and also classed as single and multiple malformations.

Result 1024 newborns with congenital malformations (13.7\%) were identified among the 7450 hospitalized newborns in neonatal intensive care unit (NICU). Mean birth weight was $2988 \pm 648 \mathrm{gr}$, mean gestational age was $37.9 \pm 2.5$ weeks. Consanguinity rate was $22.3 \%$. Prenatal diagnosis rate was $11 \%$. The most affected system was the cardiovascular system (68.8\%). Most of the malformations $(69.6 \%)$ were single malformations while $20.4 \%$ of the newborns had multiple major and $8.4 \%$ of the newborns had multiple minor malformations. On the other hand, $1.4 \%, 0.1 \%$ and $1.6 \%$ of the newborns had deformation, disruption and displasia, respectively. Chromosomal analysis was only performed $24.8 \%$ and $65.3 \%$ of them were in normal limits. The most frequently detected chromosomal abnormality was Trisomy 21 . Overall mortality rate was $15.5 \%$ among the newborns with congenital malformations.

Conclusion The most common congenital malformation was cardio-vascular malformations in our hospital. Preventing and prenatal diagnosis of congenital malformations may help to reduce perinatal mortality and morbidity. Therefore, each country should establish its own national database for prevention and management of congenital malformations.

\section{EXPRESSION OF THE NUCLEAR FACTOR OF ACTIVATED T CELLS MRNA IN HUMAN FETAL LUNG}

doi:10.1136/archdischild-2012-302724.1700

${ }^{1} \mathrm{CG}$ Ramos, 'X Sun, ${ }^{2} \mathrm{~L}$ Gonzalez-Bosc. 'Pediatrics; ${ }^{2}$ Cell Biology and Physiology, University of New Mexico, Albuquerque, NM, USA

Background and Aims The nuclear factor of activated $\mathrm{T}$ cells (NFAT) is a family of four transcription factors (c1, c2, c3 and c4) involved in vascular smooth muscle differentiation, contractility and hypertrophy. NFATc3 is required for hypoxia-induced pulmonary hypertension and for murine vascular patterning. High pulmonary vascular tone is necessary in the fetus and vasoconstrictors, such as endothelin-1 (ET-1), are required. ET-1 is a potent activator of NFAT but the role of NFAT in human lung vascular development is not known. We aim to study NFAT expression during midgestation in the human fetal lung.

Methods Human fetal lung tissue from 10 to 24 weeks of gestation was collected following elective termination (N:40). Gene expression of the NFAT isoforms $\mathrm{c} 1, \mathrm{c} 2, \mathrm{c} 3$ and $\mathrm{c} 4$ was measured in fetal lung tissue with qRT-PCR, normalized to GAPDH. Statistical analysis was performed using Spearman non-parametric correlation coefficient.

Results In the human fetal lung, NFATc1 expression increased with increasing gestational age $\left(R^{2}=0.2708\right)$. NFATc2 expression remained stable $\left(R^{2}=0.0117\right)$. NFATc3 expression increased $\left(R^{2}=\right.$ 0.1802). Conversely, NFATc4 expression decreased with advancing gestational age $\left(\mathrm{R}^{2}=0.3774\right)$.

Conclusion The NFAT isoforms are expressed during mid-gestation in the human fetal lung showing different patterns of expression. NFATc1 and NFATc3 expression increased suggesting a possible role 
in developmental vascular patterning in humans. NFATc4 expression decreased significantly and NFATc2 expression remained unchanged, requiring further research. These results suggest that NFAT is involved in fetal vascular development.

\section{DOPPLER ECHOCARDIOGRAPHIC EVALUATION OF PULMONARY ARTERY PRESSURE IN LOW BIRTH NEWBORN WITH ABDOMINAL COMPARTMENT SYNDROME AFTER ABDOMINAL SURGICAL}

doi:10.1136/archdischild-2012-302724.1701

D Dmytriiev, K Dmytriieva. Anesthesiology and Intensive Care, Vinnitsa National Medical University, Vinnitsa, Ukraine

In this prospective study 16 newborn (ranging 1 day - 28 day) with severe compartment abdominal syndrome were evaluated by Doppler echocardiography for the presence of pulmonary hypertension $(\mathrm{PH})$. The goal of this study was to determine the frequency of $\mathrm{PH}$ in newborn with severe compartment abdominal syndrome because the diagnosis of $\mathrm{PH}$ influenced the treatment of pneumonia in these newborns.

The patients who had more than $25.4 \pm 1.2 \mathrm{mmHg}$ (mean $\pm \mathrm{SD}$ ) of systolic pulmonary arterial pressure were considered to have $\mathrm{PH}$. In our study $\mathrm{PH}$ was found in 13 (81.25\%) of 16 newborn. We did not find any significant difference for the parameters including the age, weight, height, clinical symptoms, signs (tachycardia and tachypnea), and laboratory findings such as hemoglobin, $\mathrm{PCO}_{2}$, $\mathrm{HCO}_{3}$ and $\mathrm{PO}_{2}$ between the patients with and without $\mathrm{PH}(\mathrm{p}>0.01)$. However, there was a significant difference in cyanosis, cardiac failure, blood $\mathrm{pH}$ level, intra-abdominal pressure and $\mathrm{O}_{2}$ saturation measured by pulse oximetry between the patients with and without $\mathrm{PH}(\mathrm{p}<0.01)$.

\section{INCREASE PLASMA ENDOTHELIN-1 LEVELS ARE ASSOCIATED WITH LUNG HYPERTENSION IN LOW BIRTH NEWBORNS WITH OMPHALOCELE}

doi:10.1136/archdischild-2012-302724.1702

D Dmytriiev, 0 Katilov, 0 Mazulov, K Dmytriieva. Anesthesiology and Intensive Care, Vinnitsa National Medical University, Vinnitsa, Ukraine

Objective Increased pulmonary vascular resistance in low birth newborn with omphalocele is suggested, and endothelin-1 plays an important role in pulmonary vascular reactivity in newborns.

Methods We determined plasma (second sample) levels of endothelin-1 in 12 low birth newborns with omphalocele and 14 without omphalocele (gestational ages: $26.2 \pm 1.4$ and $25.4 \pm 1.6$ weeks, respectively). Blood and a second blood sample taken 18 to $40 \mathrm{~h}$ after birth were used for endothelin-1 determination by enzyme immunoassay.

Result Plasma levers ET-1 concentrations were higher than second sample ET-1 levels in both groups $(p<0.001)$. There was a significant positive correlation between second sample ET-1 and SNAPPE II $(\mathrm{r}=0.32, \mathrm{p}=0.01)$. There were no correlations between plasma ET-1 levels first sample and second sample ET-1 concentrations and 5 -min Apgar score $<6$. Duration of mechanical ventilation had a significant positive correlation with second sample ET-1 $(r=0.46$, $\mathrm{p}=0.02$ ). Plasma lever ET-1 levels did not differ between control and omphalocele (13.0 and $14.6 \mathrm{pg} / \mathrm{mL}$, respectively, $\mathrm{p}=0.80$ ). Second sample ET-1 levels had significantly higher ET-1 levels than controls (1.32 and $6.04 \mathrm{pg} / \mathrm{mL}$, respectively, $\mathrm{p}=0.001)$.

Conclusion Our low birth newborn with and without omphalocele had similar plasma ET-1 levels, whereas ET-1 levels were higher in omphalocele than in control newborns 18 to $40 \mathrm{~h}$ after birth. The increased vascular resistance in omphalocele may be related to high ET-1 levels.

\section{THE USE OF INHALED NITRIC OXIDE IN A TERTIARY PAEDIATRIC INTENSIVE CARE UNIT (PICU)}

doi:10.1136/archdischild-2012-302724.1703

${ }^{1} \mathrm{C}$ Durand, ${ }^{2} \mathrm{~S}$ Mahoney, ${ }^{2} \mathrm{~S}$ Kerr, ${ }^{2} \mathrm{~N}$ Shetty, ${ }^{2} \mathrm{D}$ Buckley. ${ }^{1}$ AlderHey Children's NHS Foundation Trust; ${ }^{2}$ PICU, AlderHey Children's NHS Foundation Trust, Liverpool, UK

Aims Inhaled nitric oxide (iNO) is used to reduce pulmonary vascular resistance and improve ventilation-perfusion mismatch. This study investigates the use of iNO in a tertiary PICU - Looking at evidence of objective assessment of its benefit (important for weaning/cessation of treatment). iNO costs $£ 40 /$ hour for the first 96 hours \& free thereafter. Total spend in this tertiary Children's Hospital in the UK was approx $£ 240,000$ per annum in 2010-11.

Methods All patients receiving iNO were identified. Data was collected prospectively from the bedside (hours on iNO) and retrospectively from case notes/electronic patient records.

Results 107 patient episodes were analysed; 63\% were admitted for cardiac surgery and $66 \%$ received iNO for $<96$ hours. Analysis focused on 52 patients over 6 months. Indication for iNO was documented in $75 \%$ of cases; $48 \%$ of these patients had an echocardiogram prior to iNO. Of those in whom the indication was Pulmonary hypertension $65 \%$ had an echo, $35 \%$ had no echo. $52 \%$ of these were cardiac surgical patients. In those in whom the indication was low oxygen saturations $36 \%$ had an echo and $64 \%$ no echo. Oxygen saturations and objective improvement measures were not routinely recorded in patient records pre/post iNO.

Conclusions Main indications for iNO were pulmonary hypertension $(36 \%)$ or low oxygen saturations $(27 \%)$. $48 \%$ of patients didn't have an echo and oxygen saturations were not documented pre/post iNO. The use and effect of an expensive though potentially beneficial drug needs to be assessed and documented to justify its continued use.

\section{CEREBRAL OXYGEN SATURATION AND EXTRACTION IN NEONATES WITH PERSISTENT PULIMONARY HYPERTENSION DURING THE FIRST 72 HOURS OF LIFE}

doi:10.1136/archdischild-2012-302724.1704

MJ Mebius, EA Verhagen, ME van der Laan, AF Bos. Division of Neonatology, Beatrix Children's Hospital, University Medical Center Groningen, University of Groningen, Groningen, The Netherlands

Background and Aim Persistent pulmonary hypertension (PPHN) is a life-threatening condition treated with high oxygen concentrations in inspired air $\left(\mathrm{fiO}_{2}\right)$. Little is known about the course of cerebral oxygen saturation $\left(\mathrm{rSO}_{2}\right)$ and extraction (FTOE) in neonates with PPHN. Our aim is to explore the course of $\mathrm{r}_{c} \mathrm{SO}_{2}$ and FTOE in neonates with PPHN during the first 72 hours of life.

Methods In term neonates with PPHN $\mathrm{r}_{c} \mathrm{SO}_{2}$ was measured with near-infrared spectroscopy. Simultaneously, arterial oxygen saturation $\left(\mathrm{SpO}_{2}\right)$ was measured and FTOE was calculated: $\left(\mathrm{SpO}_{2}-\mathrm{r}_{\mathrm{c}} \mathrm{SO}_{2}\right) /$ $\mathrm{SpO}_{2}$. We obtained clinical factors such as $\mathrm{pH}, \mathrm{pCO}_{2}$, blood pressure, NO-therapy, sedatives and inotropics. We used Wilcoxon test and Spearman's correlation to test significance.

Results We included six neonates (median GA 40+2wk, BW $3900 \mathrm{~g})$. $\mathrm{R}_{\mathrm{c}} \mathrm{SO}_{2}$ increased from day 1 to day $2(\mathrm{p}=0.028)$ and FTOE decreased from day 1 to day 2 ( $\mathrm{p}=0.027)$.

Abstract 1704 Table 1 The course of $\mathrm{rcSO}_{2}, \mathrm{SpO}_{2}$ and FTOE (median, range)

\begin{tabular}{lccc}
\hline & Day 1 & Day 2 & Day 3 \\
\hline $\mathrm{rCSO}_{2}$ & $77.5(50-88)$ & $82(54-94)$ & $78(59-94)$ \\
$\mathrm{SpO}_{2}$ & $97(92-99)$ & $97(88-98)$ & $97(88-97)$ \\
$\mathrm{FTOE}$ & $0.19(0.10-0.43)$ & $0.12(0.0-0.35)$ & $0.16(0.03-0.27)$ \\
\hline
\end{tabular}

